\title{
Host genome influences on susceptibility to HIV-I
}

\section{Amalio Telenti}

\author{
Address: Institute of Microbiology, University Hospital, University of Lausanne, Switzerland \\ from Frontiers of Retrovirology: Complex retroviruses, retroelements and their hosts \\ Montpellier, France. 21-23 September 2009 \\ Published: 24 September 2009 \\ Retrovirology 2009, 6(Suppl 2):16 doi:10.1 186/1742-4690-6-S2-16
}

This abstract is available from: http://www.retrovirology.com/content/6/S2/l6

(c) 2009 Telenti; licensee BioMed Central Ltd.

In vitro and in vivo analyses identified a significant component of heritability in cellular or host susceptibility to HIV-1. The bases for susceptibility can be traced to genetic differences (inter-species) resulting from evolutionary adaptation to exogenous (and endogenous) retroviral infections, and to intra-species and inter-individual (human) differences associated with genetic variation. We have completed large scale evolutionary analysis of genes involved in HIV life cycle and pathogenesis, as well as participating and conducting genome-wide association studies, linkage analysis, and transcriptome analysis. These studies allowed a better understanding of the influence of common human variants in HIV-1 susceptibility and define a number of experimental challenges in the filed: understanding of the role of rare and private mutations in susceptibility, and the development of better tools for the integration of data from large-scale studies. 